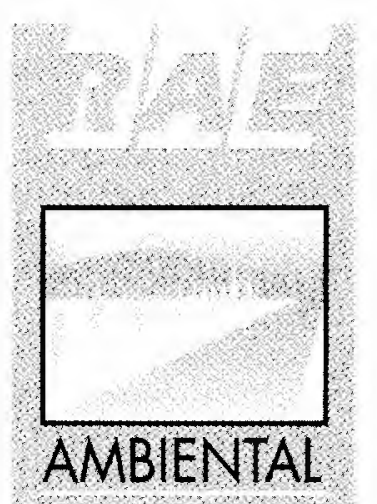

\title{
ANÁLISE DE UMA EXPERIÊNCIA DE APLICAÇÃO DA METODOLOGIA CONTINGENT VALUATION EM PESQUISA DE MEIO AMBIENTE NA CIDADE DE SÃO PAULO
}

A identificação de percepções dos problemas ambientais na busca de soluções e o envolvimento de entrevistados são algumas das potencialidades da metodologia Contingent Valuation.

The identification of the environmental perceptions and the involvement of the interviewers on finding solutions are some of the potencials of the Contingent Valuation methodology.

\section{PALAVRAS-CHAVE:}

Cidade de São Paulo, meio ambiente urbano, contingent valuation.

\section{KEY WORDS:}

São Paulo city, urban environment, contingent valuation.

\footnotetext{
* Pesquisadora Associada ao Centro de Estudos de Cultura Contemporânea (CEDEC). Professora do Departamento de Sociologia da PUC/SP, Mestre e Doutoranda em Administração na EAESP/FGV.
}

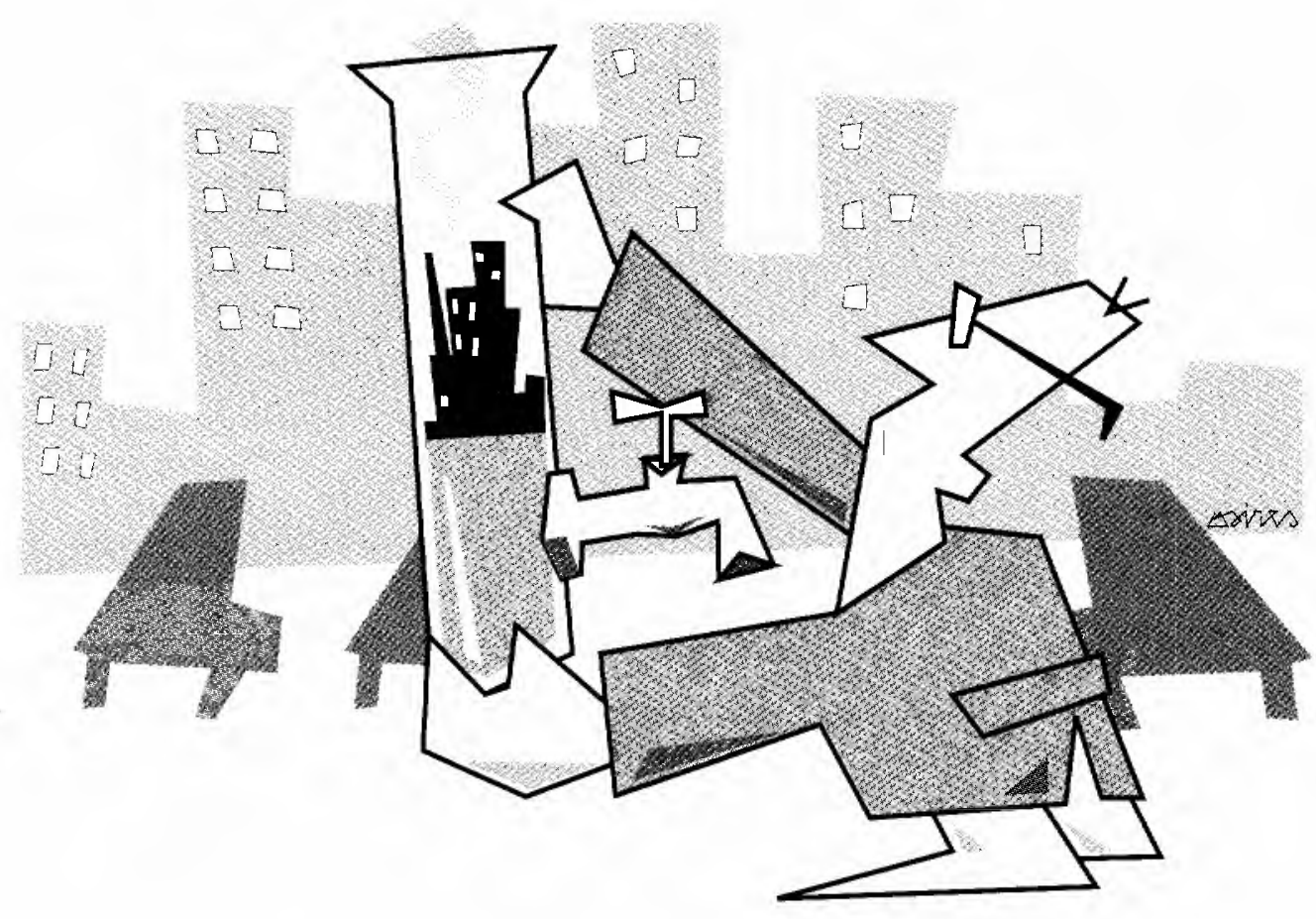


O presente trabalho propõe-se a apresentar e discutir alguns dos resultados da pesquisa "Meio Ambiente Urbano na Cidade de São Paulo" ${ }^{1}$ realizada pelo CEDEC - Centro de Estudos de Cultura Contemporânea - em 1991-92. A pesquisa constou do levantamento de uma amostra de 1.000 entrevistas domiciliares, selecionadas com base em rigorosos critérios estatísticos, a partir dos quais foram levantados dados referentes às condições ambientais vividas no cotidiano urbano. A composição da amostra foi baseada na identificação e agregação de indicadores objetivos de qualidade de vida, tais como mortalidade infantil e saneamento básico e renda, que foram agregados em seis estratos. Uma vez identificados os estratos, passou-se a identificar no espaço da cidade as zonas homogêneas. A construção de estratos, a partir de indicadores de qualidade de vida e renda, proporcionou elementos para a inserção dos dados levantados em campo numa configuração socioambiental da amostra.

O levantamento da amostra deu-se a partir da aplicação de questionário fechado formado por cinco grupos de variáveis, a saber: qualidade da água, quantidade de água, resíduos sólidos, qualidade do ar, insetos e ratos. O questionário foi basicamente composto por três seções, duas delas complementares: identificação dos problemas ambientais vividos e identificação das formas para sua solução. Uma terceira seção, diferente das anteriores, refere-se a um grupo de variáveis compostas por questōes relacionadas entre si, constituindo um conjunto ordenado e que teve por objetivo levantar dados que demonstrassem o interesse que os moradores tinham em melhorar suas condições de vida e efetuar desembolsos para a solução dos problemas ambientais percebidos. Esta seção do questionário foi aplicada pelo método Contingent Valuation.

A metodologia Contingent Valuation (técnica de valor não-monetário) refere-se fundamentalmente à questão do pagamento por melhorias na prestação de serviço por parte daqueles que o consomem e que manifestam interesse pela melhoria. Este método de mercado hipotético não está baseado na referência do mercado existente, mas baseia-se numa avaliação direta, por meio de questōes, do consenti- mento em efetuar pagamentos. Busca-se revelar o consentimento do entrevistado em efetuar pagamentos por melhorias de um bem não imediatamente concreto, como a qualidade ambiental, por exemplo, como se fosse um mercado existente. Este procedimento é útil para a revelação de preferências individuais quanto às melhorias, bem como às técnicas experimentais de solução de problemas. Segundo Barde, ${ }^{2}$ o método de mercado hipotético é muito útil porque é teoricamente aplicável a uma grande gama de problemas ambientais. A experiência tem mostrado que ele é particularmente útil e adaptável para a avaliação de bens e serviços intangíveis. O método do mercado hipotético comporta também algumas dificuldades relacionadas à sua aplicação em função principalmente do caráter hipotético da situação colocada para o entrevistado. É, pois, essencial assegurar que os entrevistados estejam incitados a responder as questões colocadas tendo em vista sua realidade socioeconômica e que o entrevistador esteja muito bem treinado, pois a qualidade dos resultados da dinâmica da oferta depende de uma boa relação entre ambos. A dinâmica da oferta consta de um jogo, onde a partir de um patamar, constituído de um valor, pode-se oferecer valores maiores ou menores, dependendo da aceitação do entrevistado.

$O$ uso da metodologia vem sendo incentivado pelo Banco Mundial como sendo um instrumento de identificação de viabilidades de solução de problemas que existem no fornecimento de serviços, a partir da disposição da população em pagar por eles. Isto porque o objetivo do incentivo do uso da metodologia prima pelo alcance de soluções técnicas adaptadas à cultura, clima, economia e condições administrativas dos países em desenvolvimento. É importante frisar que a necessidade de ajustes da solução padrão proposta é reconhecida, dada as especificidades sociopolíticas e culturais de cada país. Segundo relatório do Banco Mundial, justificando a aplicação da metodologia, quando o Estado se ausenta da produçāo de serviços como fornecimento da água e as pessoas não têm outra forma de acessá-1a, por exemplo, as mesmas tendem a pagar muito mais pelo fornecimento da iniciativa privada. "Numa lógica de
1. A pesquisa fol coordenada pelo Protessor Dr. Pedro Roberto Jacobi e pela Professora Leonor Moreira Câmara. Ela teve flnanclamento do Stokholm Environmental Institute, sendo parte integrante de um amplo projeto de análise das condições ambientais urbano/domiciliares de cidades do Terceiro Mundo.

2. BARDE, Jean-Philippe, Economie et politique de l'environment. Paris: Presses Universitaires de France, p. 91. 
saneamento com vistas à demanda, é vital dar aos usuários opções de seroiços", " daí o incentivo às soluções localizadas, cujas demandas podem ser identificadas pela metodologia do Contingent Valuation. Já no caso de serviços terceirizados, "a disposição em pagar é um bom indicador do nível do serviço a ser prestado, e a cobrança direta de taxas aos usuários seria a melhor fonte de financiamentos." ${ }^{4}$ É o caso, por exemplo, do serviço de coleta de resíduos sólidos, na cidade de São Paulo.

Ainda segundo relatório do Banco Mundial de 1992, na maioria dos países desenvolvidos os consumidores pagam por todos os gastos ordinários - operação, manutenção e serviço da dívida. Isso ocorre nos serviços de abastecimento de água, por exemplo. Já a realidade dos consumidores dos países em desenvolvimento é diferente, pois o preço efetivamente cobrado pela água é de apenas $35 \%$ do custo médio de seu fornecimento. No caso da América Latina e Caribe, por exemplo, este montante chega a apenas $21 \%$. Concomitantemente a este fato, observa-se que os consumidores urbanos, em geral, manifestam bastante interesse na melhoria dos sistemas de abastecimento, e estão dispostos a pagar o custo integral desses serviços, considerando sempre que a solução padrão deverá sofrer ajustes e será necessário um certo esforço para o atendimento dos mais pobres.

Devido à complexidade da aplicação dos conceitos da metodologia do Contingent Valuation - principalmente no que se refere às duas variáveis de interpretação: "interesse por um sistema de melhoramento ambiental" (willingness to accept) $\mathrm{e}$ "interesse em efetuar desembolsos para obtenção de melhoramento ambiental" (willingness to pay), pois cada uma é mais apropriada que a outra em situações específicas ${ }^{5}$ - optamos por analisar a relação entre ambas da forma mais básica possível. Esta análise dar-se-á a partir dos resultados obtidos na pesquisa de campo, em específico a partir de duas variáveis que compuseram esta seção do questionário, a saber: abastecimento de água e coleta de resíduos sólidos.

A análise partirá das questões denominadas de identificação crítica dos problemas, no intuito de qualificar as respostas obtidas. Em seguida, serão analisadas as inter-relações que existem entre willingness to pay e willingness to accept em sua especificidade para os problemas ambientais urbanos da cidade de São Paulo, nos três níveis diferenciados de percepção: cidade, bairro e domicílio, sendo os dois últimos analisados em comparação com o primeiro.

A pesquisa proporcionou a obtenção de uma visão geral dos diferentes níveis de percepção, a partir dos quais os problemas ambientais são percebidos pela aplicação da metodologia Contingent $\mathrm{Va}$ luation. Observou-se que, em todas as variáveis pesquisadas, apesar da existência de diferentes graus de agravos ambientais, existe um comportamento relativamente uniforme nos índices de respostas obtidas, tanto para cada uma das variáveis, para cada um dos níveis de percepção, quanto para cada um dos estratos de qualidade de vida/renda pesquisados. Revelou também que a manifestação de interesse pelo melhoramento do sistema existente, para qualquer uma das questões que compõem a dinâmica de oferta, em geral, está diretamente relacionada à percepção do morador sobre a extensão do problema. É possível observar também que a percepção deve ser analisada considerando-se as relações que o morador estabelece com a qualidade de vida no seu local de moradia, na sua vizinhança e na cidade. Estas relações são construídas a partir de níveis diferenciados de vivência, do mais geral, a cidade, modificando-se com grande variação de grau nos níveis micro-regional e domiciliar - mais cotidianos - e entre estes em menor grau. Este fato aponta um caminho para a interpretação da perspectiva do morador, a partir do domicílio e suas inter-relações com o bairro, vista como uma dimensão ampliada do cotidiano domiciliar.

No que se refere às quantias que os moradores estariam dispostos a desembolsar nos três diferentes níveis de análise 
- cidade, bairro c domicílio - verifica-se que, geralmente, a inserção social do morador e o desembolso são variáveis intervenientes na solução e no envolvimento do morador na solução proposta, mas não na percepção do problema que demanda relações simbólicas com a questão ambiental urbana. Já o nível de vivência do morador, se na cidade, no bairro ou no domicílio, revela características que contribuem para a interpretação da metodologia, segundo a qual existe uma alteração da intenção de desembolso associada ao nível da solução proposta. Assim, identifica-se como fatores-chave para a interpretação da metodologia, ou seja, a inserção social - incluindo aí não apenas a variável renda, mas também as variáveis educação, percepção de saúde e suas relações com a existência de problemas ambientais. O nível de solução, se para domicílio, bairro ou cidade, contribui para comprcender a complexidade da problematização que o morador possui a respeito dos agravos ambientais, se se trata de um problema distante ou próximo, vivido e produzido no cotidiano da vida na cidade.

Se, até agora detivemo-nos na justificativa e nos procedimentos técnicos referentes à aplicação da metodologia, cabe contudo esclarecermos algumas questões fundamentais: qual a relevância de sua aplicação no atual contexto cm que vivemos?

Os conceitos fundamentais da metodologia - Contingent Valuation willingness to accept e willingness to pay - e a relação existente entre eles são básicos para o entendimento da manifestação de interesse pela melhoria do serviço por parte do entrevistado. $O$ presente trabalho tem por objetivo demonstrar e analisar a complexidade desta manifestação a partir dos resultados concretos da aplicação da metodologia na cidade de São Paulo.

Dentre as variáveis que compuseram a pesquisa de campo, destacamos aqui apenas duas que representam dois grupos de problemas ambientais urbanos: saneamento básico e sancamento ambiental, mais especificamente quantidade de água e resíduos sólidos. Neste trabalho foram utilizados os seguintes testes estatísticos:

- regressão de proporção de Armitage: esse procedimento é adequado para os testes de hipóteses onde a variável in- dcpendente apresenta categorias qualitativas ordenáveis (estratos) e a variável dependente é composta por duas categorias nominais. Esta técnica utiliza inicialmente o teste de qui-quadrado, que estabelece uma comparação entre proporção das diferentes categorias da variável ordinal. Em seguida, testa a possivel regressão das proporções e, caso esta seja linear, apresenta o valor estimado do coeficiente angular;

- teste de Goodman para comparação de proporções por contraste nas situações onde o teste de Armitage indicou diferenças entre as categorias mas sem a existência de regressão. Esta técnica permite identificar quais as proporções que se diferenciam.

\section{BREVE CONTEXTO AMBIENTAL URBANO}

\section{Abastecimento de água}

Segundo dados de 1991, a cobertura de água no município de São Paulo abrange $93 \%$ da população. Contudo, a presença da rede de água não é uniformemente distribuída pelos bairros que compóem a cidade. Os bairros onde habitam os estratos de mais alta renda têm $100 \%$ da população abastecida. Nas regiōes periféricas, a realidade é diferente. $O$ atendimento nos bairros periféricos mais carentes nâo chega a $60 \%$ e nos bairros periféricos mais desenvolvidos está em torno de $90 \%$.

A solução provisória para satisfazer a demanda reprimida pela água, o sistema de rodízio, conquanto fosse no momento da pesquisa uma solução generalizada na cidade, abrange diferenciadamente os bairros localizados no centro e nas periferias da cidade. Conforme dados estatísticos coletados no momento da realização do trabalho de campo da pesquisa, as médias de abastecimento dos meses de junho, julho c agosto de 1991 foram as seguintes, por estrato:

\begin{tabular}{|c|c|c|c|}
\hline \multicolumn{4}{|c|}{ 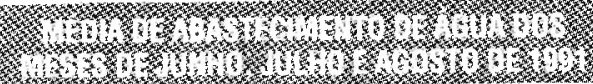 } \\
\hline estrato I & $88,46 \%$ & estrato II & $82,94 \%$ \\
\hline estrato III & $87,34 \%$ & estrato IV & $89,75 \%$ \\
\hline estrato V & $91,59 \%$ & estrato VI & $73,75 \%$ \\
\hline
\end{tabular}

Fonte: SABESP (dados fornecidos diretamente ao CEDEC). 
No momento da realização da pesquisa de campo, a capacidade das três principais fontes de abastecimento de água da cidade era a seguinte: sistema Cantareira com $26.000 \mathrm{~m}^{3} / \mathrm{s}$, Billings e reservatórios menores com $10.000 \mathrm{~m}^{3} / \mathrm{s}$ e Guarapiranga com $15.000 \mathrm{~m}^{3} / \mathrm{s}$. Esses reservatórios e os rios Pinheiros, Tietê e Tamanduateí recebem um volume total de poluição orgânica estimada em 1,2 milhão de quilos de $\mathrm{DBO} /$ dia (demanda biológica por oxigênio). O estado dos reservatórios que abastecem a cidade são classificados pela SABESP, a partir de uma gradação decrescente que vai de 1 a 4 . $O$ sistema Guarapiranga estava classificado, no momento da pesquisa, como classe 2, à qual se aplica os tratamentos convencionais. Quanto à Billings, os níveis de poluição estavam na classe 3 , à qual exige tratamento diferenciado do usado pela uniformemente distribuida pelos bairros que compöem a cidade.

6. EMPLASA. Fundamentos para o equacionamento da destinação final dos resíduos sólidos na RMSP. Versão preliminar, junho/92. lixo que ali se acumula e conviver com suas emanações. A baixa qualidade da coleta e da varrição faz com que o lixo se acumule nos espaços de circulação, nas bocas-de-lobo, causando graves problemas quando chove. Os terrenos baldios tornam-se verdadeiros depósitos de entulhos e locais de proliferação de insetos e ratos.

\section{RESULTADOS DA PESQUISA}

\section{Abastecimento de água}

Os resultados obtidos com a aplicação da metodologia reiteram a realidade do abastccimento de água na cidade no momento em que a pesquisa de campo foi realizada. $\mathrm{O}$ serviço foi avaliado pelos entrevistados como 'bom', 'regular' e 'ruim'. A aplicação do teste de regressão de proporção de Armitage com nível de significância $-1 \%$ revela-nos que existe diferença de avaliação entre os estratos para as três variáveis de avaliação. Revelou-nos também ausência de linearidade entre os estratos.

Os estratos de maior renda, com maior proporção de respostas 'boa' na avaliação do abastecimento de água, diferenciam-se dos estratos de menor renda, onde prevalece na avaliação 'regular' e 'ruim'. Se aprofundarmos a análise entre os estratos de baixa renda, verificaremos que existe entre eles uma diferenciação de precariedade, pois é no estrato de maior precariedade que a avaliação 'ruim' prevalece, mesmo sobre a 'regular'.

A manifestação de interesse por melhorias no abastecimento de água é diferente entre os diferentes estratos de qualidade de vida/renda, não existindo linearidade entre eles. Verificamos que o estrato de maior poder aquisitivo manifestou interesse de forma similar aos estratos de menor poder aquisitivo. Contudo, se destacarmos o estrato de menor poder aquisitivo, verificaremos que possui a maior manifestação de interesse na melhoria do abastecimento do que todos os demais.

Por outro lado, a expressão de interesse não significa necessariamente a disposição para pagar uma conta mensal a fim de solucionar os problemas. Verificamos que a população do estrato intermediário é a que se destaca das demais, ou seja, é a que está mais disposta a pagar uma conta mensal. 
No que se refere aos niveis mais cotidianos da vida urbana, bairro e domicílio, verificamos que a porcentagem de entrevistados que mudariam a intenção de desembolso já manifestada para a cidade é bastante pequena no conjunto dos estratos, e que as intenções manifestadas de mudança não apresentam significativas diferenças entre os estratos. Ou seja, existe uma tendência em efetuar pagamentos tanto para a cidade quanto para $o$ bairro e para o domicílio, e esta tendência não apresenta grandes diferenças entre os estratos. Cabe destacar, contudo, que os estratos tendem a diminuir a faixa de desembolso nesta situação.

\section{Resíduos sólidos}

Conquanto a coleta de resíduos sólidos seja realizada no mínimo três vezes por semana na cidade como um todo, segundo informações da Prefeitura, em algumas regiões mais de três vezes por semana e até diariamente na região central, constatamos que a avaliação da qualidade do serviço não se dá de forma homogênea entre os diferentes estratos. A aplicação da regressão de proporções de Armitage com nível de significância $-1 \%$ demonstrou que a população como um todo apresenta diferentes graus de avaliação do serviçco. Esta realidade foi observada para a avaliação 'boa', 'regular' e 'ruim'.

Constatada a existência de diferenças de avaliação entre os estratos, torna-se necessário conhecer como é que ela ocorre entre eles. Verifica-se que existe linearidade no conjunto dos estratos e das variáveis de avaliação. No caso da variável 'boa' constatamos que, quanto maior a precariedade da qualidade de vida e renda, diminui em média $8,9 \%$ a porcentagem dos que dizem que o serviço de coleta de resíduos sólidos é 'boa' $(b=-8,9 \%)$ $(\mathrm{P}=1 \%)$. Para a variável 'regular', verificamos que o aumento da porcentagem é em média $4,0 \%(\mathrm{~b}=+4,0 \%)$ e para a variável 'ruim' é de $10 \%(b=+10 \%)$.

A constatação da avaliação do serviço por estratos revela que sua qualidade é questionada tanto mais à medida que se agravam as condições ambientais vividas pelos moradores e a renda decresce. No que se refere à coleta de resíduos sólidos, a pesquisa demonstrou que o cer- ne da avaliação não foi a sua ausência e sim a sua qualidade. Isto demonstra, portanto, a necessidade de melhorias no serviço prestado em regióes da cidade habitadas pela população mais carente e em piores condições ambientais.

A metodologia revela que, apesar da avaliação do serviço ocorrer de forma linear no conjunto dos estratos, a manifestação de interesse por sua melhoria não ocorre da mesma forma, ou seja, não apresenta linearidade. Verifica-se que a população do estrato de maior poder aquisitivo manifesta menor interesse pelo sistema de melhoria do que a população dos estratos mais carentes e, entre estes últimos, o que apresenta maior precariedade é o que revela maior interesse em melhorar o sistema de coleta de resíduos sólidos. Este fato demonstra que o interesse em melhorar o sistema de coleta está diretamente relacionado com a avaliação que os moradores fazem dele.

No que se refere à disposição em pagar conta mensal, verifica-se que não existe linearidade nas respostas dos diferentes estratos. Verifica-se que os estratos de maior renda apresentam a mesma proporção de respostas positivas apresentadas pelos estratos de renda menor. Apenas o estrato de maior precariedade destaca-se dos demais com uma porcentagem de respostas positivas maior que a de todos os demais.

Já no que se refere aos níveis bairro e domicílio, ou seja, se as melhorias ambientais na coleta de resíduos sólidos fossem oferecidas apenas para o bairro e o domicílio, verificamos que, no geral, apenas uma pequena parcela alteraria o interesse manifestado para a cidade como um todo. E, mesmo nesta pequena parcela, não foram verificadas diferenças entre os diferentes estratos de qualidade de vida e renda, conquanto tendam a diminuir a oferta.

\section{CONSIDERAÇÕES ACERCA DOS RESULTADOS DA PESQUISA}

- Conquanto o estrato de renda e qualidade de vida, no qual toda a pesquisa foi baseada, seja um condicionante fundamental no que se refere à exposição da população aos problemas ambientais, verifica-se que existe uma 
disposição generalizada de procurar soluções para seu enfrentamento. Este interesse não se manifesta de forma similar nos diferentes cstratos, porém de forma muito aproximada. A população do estrato de menor renda é a que apresenta maior porcentagem de respostas positivas, tanto para a variável abastecimento de água, quanto para a variável resíduos sólidos. Esta constatação leva a reiterar que as diferenças das avaliações dos serviços são condicionantes da manifestação do grau de interesse no sistema de melhoria.

- No que se refere ao pagamento de uma conta mensal para a solução dos problemas aqui expostos, verifica-se que, no geral, a população dos estratos de renda mais baixa está disposta a efetuar pagamentos na mesma proporção da população dos estratos de renda mais alta. As variáveis aqui apresentadas demonstram que a renda condiciona a exposição e vulnerabilidade da população aos problemas ambientais, mas não está diretamente relacionada com a intenção de efetuar pagamentos para a solução dos problemas percebidos. Verifica-se também que o valor que a população dos diferentes estratos está disposta a desembolsar apresenta uma relação direta com o valor inicial proposto na dinâmica da oferta, ou seja, se partir de patamares maiores, o resultado tende a ser um desembolso maior e vice-versa.

- A análise conjunta da manifestação de interesse por um sistema de melhoria e a disposição em efetuar pagamentos mensais por ele revela que, nos casos aqui apresentados, existe uma forte relação onde se manifesta o envolvimento dos entrevistados com a solução dos problemas vivenciados.
- A pesquisa revelou que a renda não é uma variável excludente na intenção de efetuar pagamentos. O importante a destacar aqui é que a percepção dos problemas cotidianos e sua percepção pelo morador acaba tendo peso maior que sua situação econômica. É o caso, por exemplo, dos estratos de baixa renda, onde verificamos ocorrer relativamente as mesmas porcentagens de respostas referentes ao interesse pelo sistema de melhoria c de disposição em efetuar pagamento mensal. Nesses estratos, verifica-se que a população está disposta a efetuar pagamento de quantias muito próximas de desembolsos das reveladas pela população dos estratos de renda mais elevada.

- Com relação aos diferentes níveis de interesse por melhorias ambientais e de desembolsos, se para a cidade como um todo, para o bairro ou para o domicílio, verificase que tanto a variável abastecimento público quanto a coleta de resíduos sólidos apresentam o mesmo comportamento. Neste sentido, tanto a população dos estratos de alta renda quanto a população dos estratos de baixa renda em grande parte não alterariam a quantia oferecida para a cidade se o sistema fosse oferecido apenas para o bairro ou o domicílio. Não existem, pois, tendências de privilegiar os níveis de vivência cotidiana em detrimento do nível mais geral.

Até agora expôs-se algumas considerações referentes à experiência de aplicação da metodologia Contingent Valuation. Cabe-nos agora estabelecer suas potencialidades e sua crítica no contexto de sua aplicação, ou seja, o que pode significar o interesse que os moradores manifestaram pelas melhorias ambientais e o pagamento por elas? Indo um 
pouco mais além, o que pode significar a opção metodológica?

Dentre as potencialidades da metodologia, destaca-se a identificação de percepções dos problemas ambientais e do envolvimento dos entrevistados em buscar soluções independentemente dos estratos de qualidade de vida e renda ao qual pertençam. Neste sentido, ações locais podem ser implementadas. Além da possibilidade de soluções localizadas com o envolvimento da população consumidora dos serviços, tem-se também a possibilidade de abertura de um grande mercado a partir da terceirização dos serviços, prática cada vez mais comum nos municípios. É o caso, por exemplo, dos serviços de abastecimento de água. Atualmente, grande número de municípios não tem meios de efetuar a ampliação das redes de abastecimento e tem incentivado a participação de empresas privadas.

Por outro lado, o que pode ser uma solução, pode ser também um enorme problema. Não é suficiente indagar ao entrevistado se ele estaria disposto a efetuar pagamentos para solucionar o problema da coleta de resíduos sólidos, por exemplo. É imprescindível indagar também que tipo de solução está em jogo, se iniciativas adequadas às necessidades locais, transparentes ao controle local, ou iniciativas pautadas em megaempreendimentos, onde a cartelização do serviço está presente. Temos como exemplo o caso da coleta de resíduos sólidos e da polêmica recentemente levantada de um possível processo de cartelização.

Entende-se que o interesse em melhorias ambientais pode ser um bom indicador do nível de crítica que a população consumidora dos diferentes estratos faz em relação aos serviços, e que a disposição em efetuar pagamentos pode indicar o grau de satisfação com o serviço prestado, pois existe uma tendência muito valorizada na metodologia do Contingent Valuation, segundo a qual as pessoas tendem a valorizar tudo aquilo que não têm ou estão na iminência de perder. Neste sentido, pode ser um valioso indicador de prioridades na formulação de políticas públicas. A pesquisa ainda revela a necessidade de a população buscar soluções alternativas para as ineficiências na produção de serviços pelo Estado ou pela iniciativa privada. Vale destacar que, no momento da pesquisa de campo, dada a insuficiência da oferta de água para o abastecimento, fazia-se uso do sistema de rodízio, ou ainda que, neste mesmo período, houve uma greve de lixeiros na cidade. Estes fatos poderiam criar a consciência da busca de soluções alternativas mais seguras, no que se refere à gestão dos serviços em termos de confiabilidade e de melhor qualidade. Nesta direção, os resultados da pesquisa tendem a chamar a atenção para um novo campo de possibilidade tanto para empreendimentos quanto para a gestão ambiental.

Por outro lado, a realidade socioeconômica do país nos leva a indagar se a solução dos problemas ambientais, em específico os aqui tratados, passariam necessariamente pela saída do Estado do mercado ou, ainda, se existiria a possibilidade de ação dos órgãos estatais em conjunto com a sociedade. A prática vem mostrando que isto é cada vez mais possível.

\section{BIBLIOGRAFIA SUPLEMENTAR}

WACOBI, Pedro R.(Coord.), CÂMARA, Leonor M. Environmental problems facing urban households in the city of São Paulo. Brasil. Final report. São Paulo: CEDEC, 1993

簿 WHITTINGTON, D. et al. Estimating the willingness to pay for water services in developing countries: a case study of contingent valuation surveys in Southern Haiti. Economic Development and Cultural Change, v.38, n.2. 1990. Ј 